sc $\mid$ nat $^{\mathbf{*}}$

\author{
Chemistry \\ Platform of the Swiss Academy of Sciences
}

\section{Chemistry Travel Award by SCNAT, SCS and SSFC}

\section{Leo Merz*}

${ }^{*}$ Correspondence: Dr. L. Merz, Swiss Academy of Sciences (SCNAT),

Platform Chemistry, Laupenstrasse 7, CH-3008 Bern, E-mail: chemistry@scnat.ch

The «Platform Chemistry» of the Swiss Academy of Sciences (SCNAT) together with the Swiss Chemical Society (SCS), and the Swiss Society for Food Chemistry (SSFC) announced the «2016 Chemistry Travel Award». This program aims to support excellent $\mathrm{PhD}$ students in chemical sciences through sponsoring them to participate in an international conference. Students from all fields of chemistry and from any Swiss institution were invited to participate and many applications were received. The selection committee is set up with representatives of the three organisors and who are working in diverse fields of chemistry: Prof. Dr. Christian Bochet (SCS, University of Fribourg), Dr. Thomas Gude (SSFC, Swiss Quality Testing Services), Dr. Marc Suter (SCS, Eawag), and Prof. Dr. Oliver Wenger (SCNAT, University of Basel). They each reviewed and rated all of the applications (except their own students'), based primarily on the submitted conference abstract and the scientific achievements.

On behalf of SCNAT, SCS and SSFC we hereby congratulate the winners and wish them a very successful conference participation.

We proudly present the winners of the «2016 Chemistry Travel Award»:

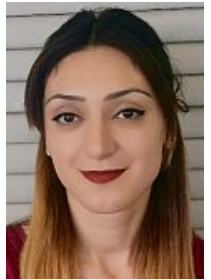

\section{Ani Baghdasaryan}

Group: Prof. Dr. Thomas Bürgi

Conference: ISSPIC XVIII - International Symposium on Small Particles and Inorganic Clusters

Title: 'Fast synthesis and characterization of subnanometer-sized thiolated copper clusters'

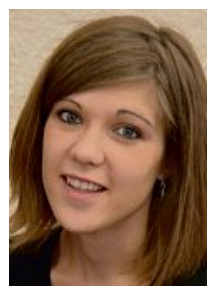

\section{Karine Baudet}

Group: Prof. Dr. Claude Piguet

Conference: $42^{\text {nd }}$ edition of the International Conference on Coordination Chemistry (ICCC42)

Title: 'A Novel Thermodynamic Analysis of Intermolecular Association Processes'

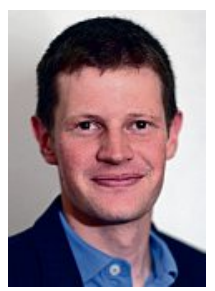

\section{Sebastian Benz}

Group: Prof. Dr. Stefan Matile Conference: $27^{\text {th }}$ International Symposium on Organic Chemistry of Sulfur Title: 'From Sulfur Redox Switches for Anion- $\pi$ Catalysis to Chalcogen Bonds'

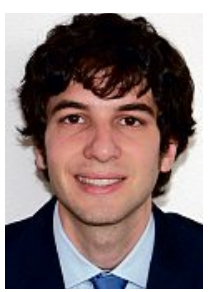

Vasco Bolis

Group: Prof. Dr. Konrad Hungerbühler Conference: $26^{\text {th }}$ European Symposium on Computer Aided Process Engineering (ESCAPE 26)

Title: 'Optimal Design of Industrial Wasteto-Energy Networks'

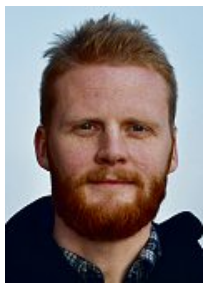

Alexander Bork

Group: Prof. Dr. Jennifer Rupp

Conference: Nonstoichiometric Compounds VI

Title: 'Two-step thermochemical solarto-fuel efficiency computation of strontium and chromium doped lanthanum manganite perovskite oxides using CALPHAD'

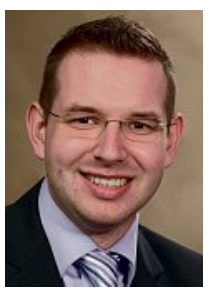

Lukas Bregy

Group: Prof. Dr. Renato Zenobi

Conference: $21^{\text {th }}$ International Mass Spectrometry Conference (IMSC 2016) Title: 'Real time SESI-MS analysis of exhaled breath identifies altered metabolic signature in chronic obstructive pulmonary disease' 

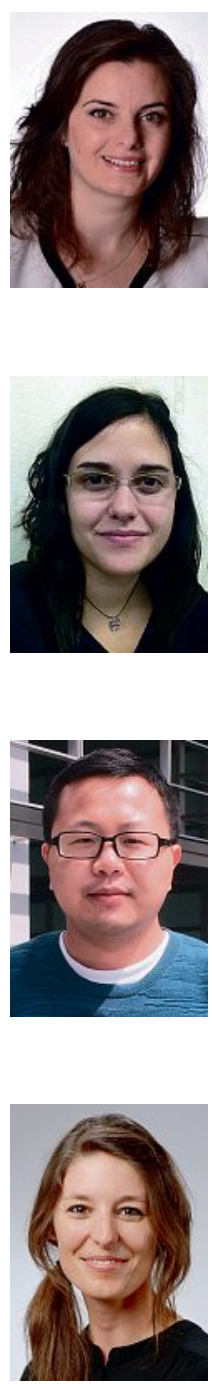

Elena-Diana Burghelea

Group: Prof. Dr. Carlotta Guiducci

Conference: The $20^{\text {th }}$ International Conference on Miniaturized Systems for Chemistry and Life Sciences

Title: 'Small-drug quantification from wholeblood within paper-based microstructures for Point-of-Care Therapeutic Drug Monitoring'

\section{Teresa Delgado Pérez}

Group: Prof. Dr. Andreas Hauser and Dr. Céline Besnard

Conference: Applied Nanotechnology and Nanoscience International Conference Title: 'Structural Investigation of the HSto LS Relaxation Dynamics on the Porous Coordination Network [Fe(pz)Pt(CN) $)_{4}$ '

\section{Yun Ding}

Group: Prof. Dr. Andrew deMello Conference: 2016 International Conference of Microfluidics, Nanofluidics and Lab-ona-Chip

Title: 'A highly efficient droplet-based microfluidic strategy for next-generation sequencing in single cell level'

\section{Adriana Edenharter}

Group: Prof. Dr. Karl-Heinz Altmann Conference: $21^{\text {st }}$ International Conference on Organic Synthesis (ICOS-21)

Title: 'Total synthesis of leiodolide A'

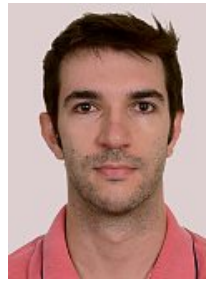

\section{Lucas Foppa}

Group: Dr. Aleix Comas-Vives and

Prof. Dr. Christophe Copéret

Conference: Gordon Research

Conference 'Catalysis - From Theory to

Commercialization'

Title: 'Dry reforming and competitive reactions on $\mathrm{Ni}, \mathrm{Pd}$ and $\mathrm{Pt}$ metal surfaces from DFT calculations and microkinetic modeling simulations'

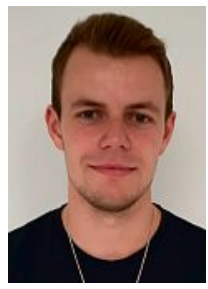

\section{Angelo Frei}

Group: Prof. Dr. Roger Alberto

Conference: $8^{\text {th }}$ Asian Biological Inorganic Chemistry Conference

Title: 'Multifunctional Cp-Ligands, a New Versatile Toolbox for the Development of Theranostic Agents'

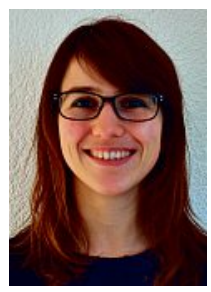

\section{Agni Gavriilidou}

Group: Prof. Dr. Zenobi Renato

Conference: $21^{\text {st }}$ International Mass

Spectrometry Conference

Title: 'Studying non-covalent interactions with nano ESI-MS: An insight into the allosteric mechanism of M2 pyruvate kinase isoform (PKM2)'

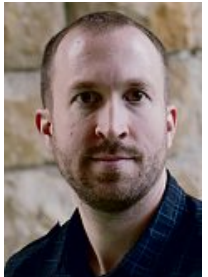

\section{Christoph Geers}

Group: Prof. Dr. Alke Fink

Conference: $11^{\text {th }}$ International Conference on the Scientific and Clinical Applications of Magnetic Carriers

Title: 'An abstract approach to quantify the heating power of magnetic nanoparticles'

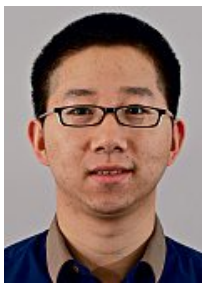

\section{Minglong He}

Group: Prof. Dr. Petr Novák

Conference: $67^{\text {th }}$ Annual Meeting of the International Society of Electrochemistry Title: 'Ageing Phenomena in High-voltage Aqueous Supercapacitors Investigated by In Situ Gas Analysis'

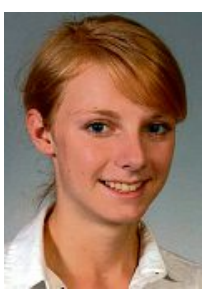

\section{Tamara Husch}

Group: Prof. Dr. Markus Reiher

Conference: Molecular Quantum Mechanics Title: 'Assessment of semiempirical methods for transition metal complexes'

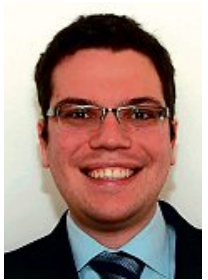

\section{Patrick Isenegger}

Group: Prof. Dr. Andreas Pfaltz

Conference: Gordon Research Conference on Stereochemistry

Title: 'Asymmetric Morita-Baylis-Hillman Reaction: Catalyst Development and Mechanistic Insights'

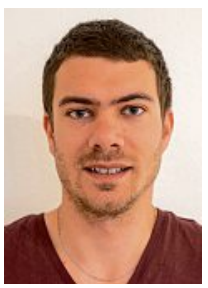

\section{Ugo Jacovella}

Group: Prof. Dr. Frédéric Merkt Conference: International Symposium on Molecular Spectroscopy

Title: 'Infrared spectroscopy of ions in selected rotational and spin-orbit states'

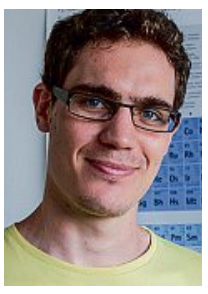

\section{Xavier Jeanbourquin}

Group: Prof. Dr. Kevin Sivula

Conference: $253^{\text {rd }}$ ACS National Meeting \& Exposition

Title: 'Aliphatically-linked conjugated small molecules for crystal structure engineering and stability enhancement in organic solar cells'

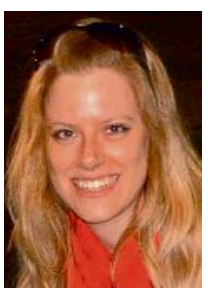

\section{Evelyne Joliat}

Group: Prof. Dr. Roger Alberto

Conference: International Conference on Coordination Chemistry (ICCC) 2016

Title: 'Cobalt Complexes Based on Bipyridine Macrocycles: Properties and Photocatalytic Proton Reduction' 


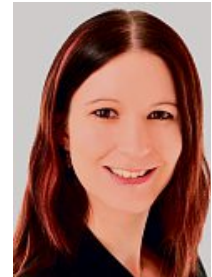

Sarah Keller

Group: Prof. Dr. C. E. Housecroft and

Prof. Dr. E. C. Constable

Conference: $99^{\text {th }}$ Canadian Chemistry

Conference and Exhibition

Title: 'Heteroleptic light-emitting copper(I)

complexes with applications in light-emitting electrochemical cells (LECs)'

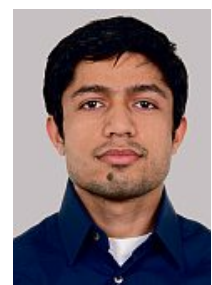

Rajesh Koirala

Group: Prof. Dr. Sotiris E. Pratsinis

Conference: The $16^{\text {th }}$ International Congress

on Catalysis (ICC-16)

Title: 'Flame-made Single and Mixed Oxides

Supported Cobalt Catalysts for Oxidative

Dehydrogenation of Ethane'

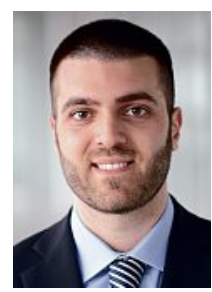

Mario Francesco Mirabelli

Group: Prof. Dr. Renato Zenobi

Conference: International Mass Spectrometry

Conference (IMSC 2016)

Title: 'Observing proton transfer reactions inside the MALDI plume: experimental and theoretical insight into MALDI gas-phase processes'

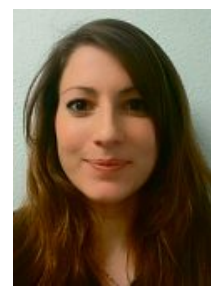

\section{Laëtitia Misson}

Group: Prof. Dr. Florian P. Seebeck

Conference: $8^{\text {th }}$ International Congress

on Biocatalysis (biocat2016)

Title: 'Identification of a new family of aromatic amino acid betaine synthases'

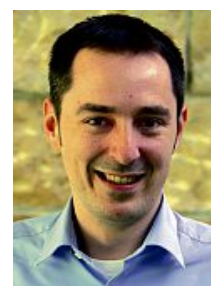

\section{Christophe Monnier}

Group: Prof. Dr. Alke Petri-Fink

Conference: $11^{\text {th }}$ International Conference on the Scientific and Clinical Applications of Magnetic Carriers

Title: 'Lock-in thermography: Using heat as an indicator for stability, quantity and distribution of magnetic nanoparticles in biological systems'

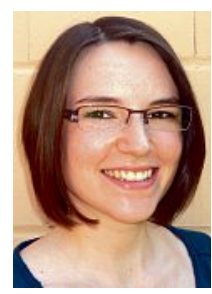

Julia Nomrowski

Group: Prof. Dr. Oliver S. Wenger

Conference: 25. Lecture Conference on Photochemistry

Title: 'Photoinduced electron accumulation in a molecular triad'

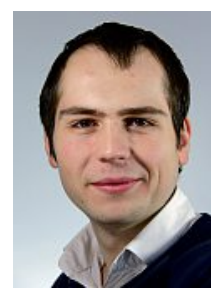

Vladimir Paunović

Group: Prof. Dr. Javier Pérez-Ramírez

Conference: $16^{\text {th }}$ International Congress on Catalysis

Title: 'Catalyst design for $\mathrm{HBr}$-mediated natural gas upgrading via combined heterogeneous-homogeneous pathways'

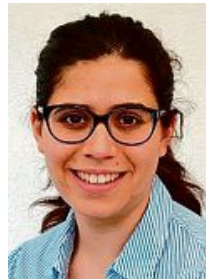

\section{Laura Piveteau}

Group: Prof. Dr. Maksym V. Kovalenko Conference: Gordon Research Conference on Colloidal Semiconductor Nanocrystals Title: 'Atomistic Description of Colloidal Semiconductor Nanocrystals using Dynamic Nuclear Polarization NMR Spectroscopy'
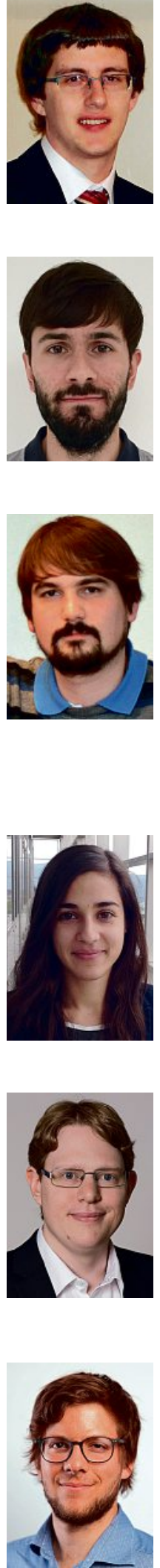

Robert Pollice

Group: Prof. Dr. Peter Chen

Conference: $15^{\text {th }}$ Belgian Organic Synthesis Symposium (BOSS XV)

Title: 'Expansion of the Concept of Nonlinear Effects in Catalytic Reactions beyond Asymmetric Catalysis'

\section{Lucas Prieto Gonzalez-Posada}

Group: PD. Dr. Felix Zelder

Conference: $8^{\text {th }}$ Asian Biological Inorganic Chemistry Conference (AsBIC8)

Title: 'A Reversible Route for the Selective Scission and Full Repair of the Corrin Macrocycle in Vitamin B12'

\section{Peter Ribar}

Group: Dr. Michal Juríček and

Prof. Dr. Marcel Mayor

Conference: The $15^{\text {th }}$ International Conference on Molecule-Based Magnets (ICMM 2016) and Workshop for Young Investigators on Functional Molecular Materials and Molecular Related Magnetism (Rising Star Preconference)

Title: 'Synthesis of persistent derivative of open-shell graphene fragment triangulene'

\section{Laura Rodriguez Garcia}

Group: Prof. Dr. Konrad Hungerbühler

Conference: $16^{\text {th }}$ International Congress on Catalysis

Title: 'Discrimination of active species in liquid-phase hydrogenation on supported noble metal catalyst by operando spectroscopy'

\section{Sebastian Schmidt}

Group: Prof. Dr. Sébastien Sallard

Conference: $67^{\text {th }}$ Annual Meeting of the Internationan Society of Electrochemistry Title: 'Lithium Iron Methylene Diphosphonate, an Organic-Inorganic Hybrid Material for Positive and Negative Li-ion Battery Electrodes'

\section{Elia Schneider}

Group: Prof. Dr. Wendelin J. Stark

Conference: AIChE 2016

Title: 'Click and release: fluoride cleavable linker for mild bioorthogonal separation on magnetic nanoparticles' 


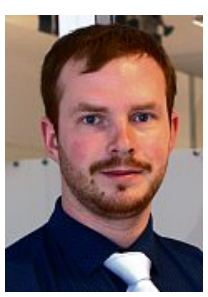

Evgeny Smirnov

Group: Prof. Dr. Hubert Girault

Conference: $67^{\text {th }}$ Annual Meeting of the International Society of Electrochemistry Title: 'Electron Transfer Reaction at LiquidLiquid Interfaces: What is the Correct Mechanism?'

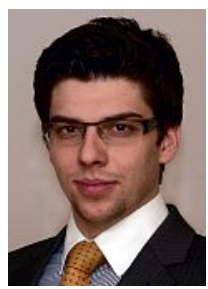

\section{Michael Sokolov}

Group: Prof. Dr. Massimo Morbidelli Conference: European Symposium on Biochemical Engineering Sciences Title: 1) 'Robust factor selection in biosimilar $\mathrm{mAb}$ process development using high throughput experiments and multivariate data analysis'

2) 'Dynamic product quality prediction at multiple scales in the process development for mAbs'

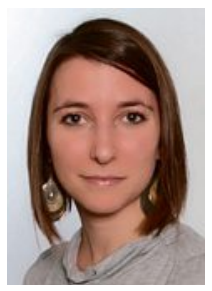

\section{Alessia Stornetta}

Group: Prof. Dr. Shana J. Sturla

Conference: $64^{\text {th }}$ ASMS Conference on Mass

Spectrometry and Allied Topics

Title: 'High-Resolution/Accurate-Mass

LC-MS3 Screening and SRM Relative

Quantitation of DNA Adducts as Biomarkers of Drug Susceptibility'

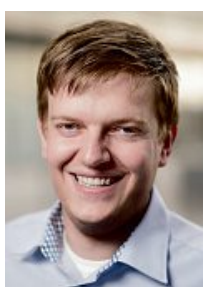

\section{Peter Tiefenböck}

Group: Prof. Dr. Jean-Christophe Leroux Conference: Globalization of Pharmaceutics Education Network (GPEN 2016)

Title: 'A novel cell engineering platform based on microinjection of enzyme-loaded liposomes'

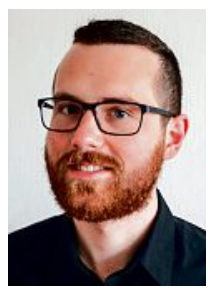

Alexander Zech

Group: Prof. Dr. Tomasz A. Wesolowski Conference: The Ninth Congress of the International Society for Theoretical Chemical Physics (ISTCP IX)

Title: FDE-ADC: Multiscale density embedding with an accurate wavefunction method.

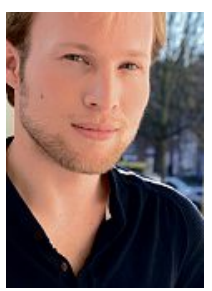

\section{Guido Zeegers}

Group: Prof. Dr. Renato Zenobi

Conference: $21^{\text {st }}$ International Mass

Spectrometry Conference (IMSC 2016)

Title: 'Evidence for laser-induced redoxreactions between added trifluoroacetate salts and substrate material during polystyrene/ DCTB matrix-assisted laser desorption/ ionization'

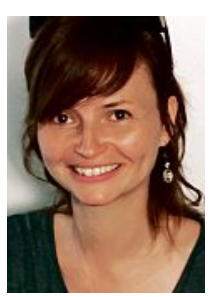

\section{Susann Zelger-Paulus}

Group: Prof. Dr. Roland Sigel

Conference: RNA structure meets function, EMBO workshop

Title: 'Single-molecule FRET study of an encapsulated group II intron'

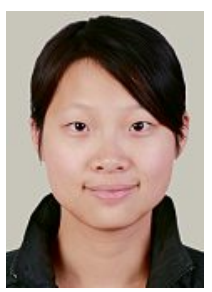

\section{Bei Zhang}

Group: Prof. Dr. Thomas Buergi

Conference: $18^{\text {th }}$ International Symposium on Small Particles and Inorganic Clusters (ISSPIC XVIII)

Title: 'Ag doped Au38(SC2H4Ph)24

nanocluster: metal migration and chiroptical properties'

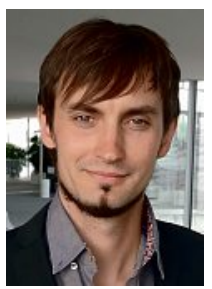

\section{Vitalijs Zubkovs}

Group: Prof. Dr. Ardemis Boghossian Conference: $229^{\text {th }}$ Electrochemical Society Meeting

Title: 'Engineering Smart Wrappings for Next Generation Single- Walled Carbon Nanotube (SWCNT) Sensors'

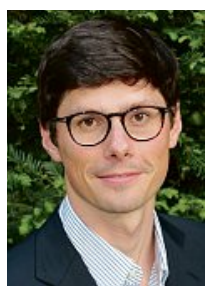

Michael Zumstein

Group: Dr. Michael Sander

Conference: GRC: Environmental Sciences:

Water

Title: 'Enzymatic and Microbial Degradation of Polyesters in Soils'
Additional information about the «Platform Chemistry» and its activities may be found at chemistry.scnat.ch

Do not miss the «2017 Chemistry Travel Award», which will be announced early in 2017 on chemistry.scnat.ch/travel_award and in CHIMIA. 